\title{
PLANEJAMENTO AMBIENTAL E DESENVOLVIMENTO DO ECOTURISMO
}

\author{
Renato Dell' Erba Ortega* \\ João Roberto Cilento Winther** \\ Wandir Ribeiro***
}

\begin{abstract}
RESUMO: O ecoturismo vem sendo apontado como uma das alternativas econômicas mais importantes para exploração de ecossistemas a serem conservados. Porém, a crescente demanda por atividades "ecológicas", tendo como base o contado direto com ambientes naturais, e como pressuposto a aquisição de conhecimento sobre o meio, tem evidenciado a carência de um planejamento técnico-político para o setor, buscando alcançar, na integração com as políticas nacional e estaduais de meio ambiente, e com o desenvolvimento regional e local, um eficaz desempenho econômico.
\end{abstract}

UNITERMOS: Ecoturismo: planejamento, desenvolvimento. Planejamento: turismo ecológico; ecoturismo.

ABSTRACT: The ecological tourism has been indicated as one of the most important altematives to explore consen'ed ecossistems. The growing demand for "ecological" activities, based on the close contact with natural areas and the consequent knowledge acquisition, has shown the lack of a technical and political planning, sceking an optimum economical performance with national and regional policies, intergrated with their development.

KEY WORDS: Ecological tourism: planning, development. Planning: ecological tourism; eco-tourism.

(*) Geólogo pelo Instituto Geológico da USP. Superintendente do Departamento de Estudos Ambientais da Engea - Avaliações. Estudos do Património e Engenharia Ltda.

(**) Advogado pela Pontifícia Universidade Católica de São Paulo. Membro da equipe técnica da Engea Ltda.

(***) Engenheiro Agrônomo/Florestal pela Escola Superior de Agricultura "Luiz de Queiroz" da USP. Membro da equipe tcnica da Engea Ltda.

End. para corresp.: Al. Franca, 219 - CEP 01422 - So Paulo - SP - Brasil. 


\section{INTRODUÇÃo}

A preocupação com a vida em todas as suas formas e com o bemestar da espécie humana através da garantia de um meio ambiente saudável e equilibrado e da renovabilidade dos recursos naturais tem levado a sociedade industrial, e a forma pela qual organizou a econo. mia mundial, a mudanças significativas de rumo e/ou comportamento, ainda que pela pressão de diversos segmentos da sociedade civil formadores da opinião pública. Embora essas mudanças não tenham provocado uma ruptura total dos modos de agir e pensar do atual sistema de produção, optando por um tipo de desenvolvimento diferenciado, alguns paradigmas têm surgido priorizando novas concepções de de senvolvimento onde a demanda pela qualidade tem se sobreposto à quantidade.

Nesse sentido, o contato do homem com a natureza vem sendo redescoberto como fator estratégico do bem estar físico e mental, es pecializando-se como mercadoria para as sociedades urbanas, cada vez mais afastadas desse convívio e conduzidas a um ritmo de vida altamente estressante. Ainda que a preocupação com o meio ambiente se mostre como estratégia mercadológica para a manutenção da produção nos diversos setores da economia, a componente ambiental tem imposto, para qualquer intervenção econômica, a melhoria de qualidade de vida das populações humanas como índice da produtividade almejada.

É por estas razōes que o setor turístico, intrinsecamente relacionado com os empreendimentos imobiliários, tem privilegiado a procura por locais que forneçam áreas agradáveis ao lazer, com condiçōes saudáveis, belas paisagens e variedade de atraçōes naturais, muito em bora o assim chamado "turismo ecológico" ou "ecoturismo" tenha surgido pelo modismo gerado através da "mídia" e dos diversos segmentos da economia ávidos por mais um filão do mercado, sem o res paldo conceitual e metodológico necessário à sua estruturação.

Um exemplo desses fatos verifica-se na série crescente de condomínios "ecológicos", que vêm sendo implantados em áreas de inte resse ambiental ou nas programações de hotéis e agências de turismo anunciando excursōes a áreas de florestas, cachoeiras, cavernas etc. Outras agências oferecem percursos em trilhas e cursos de "sobrevivência na selva".

Mas, o que pode acarretar a exploração turística de áreas naturais, sem um planejamento e orientação adequados? - Provocam-se muitas vezes ações altamente nocivas ao meio, tanto, em diversos parques nacionais e estaduais, quanto em áreas particulares destinadas a esse fim. Isto ocorre pois, mesmo que temporariamente, o turismo desordenado impõe processos de ocupação do espaço que acabam por descaracterizar a paisagem e colocar o meio em risco de desequilíbrio.

\section{DESENVOLVIMENTO SUSTENTADO E ECOTURISMO}

A tese ambientalista da sustentabilidade no desenvolvimento económico das naçōes foi incorporada pela Comissão Mundial de Meio Ambiente e Desenvolvimento - CMMAD - da ONU, e convertida em ponto central do relatório "Nosso Futuro Comum" ou "Relatório Brundtland"'. Nos termos desse relatório a sustentabilidade se acopla a um novo padrão de desenvolvimento e crescimento econômico que deve ser garantido. Assim, desenvovimento sustentável* seria

uma correçäo, uma retomada do crescimento, alterando a qualidade do desenvolvimento, a fiun de tomá-lo menos intensivo no uso de matérias-primas c mais cqüitativo para todos, ...Um processo de mudança no qual a exploraçào dos recursos, a orientaçäo dos investimentos, os nımos do desenvolvimento tecnológico e a mudança institucional estäo de acordo com as necessidades atuais e futuras.

Segundo o professor Pinheiro Machado, da Universidade Federal de Santa Catarina, o desenvolvimento sustentado deve atender aos seguintes princípios:

a) ser cientificamente embasado;

b) ser ecologicamente equilibrado;

c) ser energicamente renovável;

d) ser economicamente setorial;

e) ser tecnicamente exeqüível;

f) ser culturalmente assimilável;

g) ser socialmente justo. ${ }^{3}$

Ainda que estes conceitos de sustentabilidade do desenvolvimento sejam discutíveis sob o ponto de vista da tecnologia disponível, que se baseia no consumo acelerado dos recursos finitos, irrecuperáveis e insubstituíveis, nossa sociedade, se quiser sobreviver, terá muito que aprender com as tecnologias naturais que são auto-reguladoras e que vivem de recursos eternamente recicláveis. ${ }^{4}$

Nesse contexto, a atividade turística é caractrizada como o segmento económico que se propōe a colocar o homem em contato mais direto com o patrimônio natural, sendo realizada em áreas de relevante interesse ecológico. Tem a missão de despertar no público sua conscientização para os dilemas que a questão do desenvolvimento $x$ meio

$\left({ }^{*}\right)$ Ver também documento da UICN - União Internacional para Conservaçāo da Natureza -, que trata da estratégia mundial para a conservação".? 
ambiente tem provocado em nossa sociedade, combatendo a visão an tropocêntrica e maniqueísta de que o homem se opõe à natureza, ou que a domina, ou, ainda, que dela não faz parte, a partir do conhecimento dos ecossistemas visitados. Trata-se portanto de um turismo orientado, onde educação ambiental e lazer se conjugam para promover a aquisição de conhecimento.

Fica claro portanto que o ecoturismo se diferencia das atividades comuns de lazer, não podendo prescindir de respaldo técnico-científico para sua estruturação enquanto atividade "ecológica". No que tange a sua implantação pelo setor privado ou público, o aspecto econô. mico não pode ser desprezado, mas deve observar as diretrizes de zoneamento econômico-ecológico, provendo tais atividades no planejamento estratégico ou planos de manejo de cada região e/ou sítios a serem desenvolvidos turisticamente.

Desse modo, em que pese a inexistência de uma política naciona específica*, mister se faz a planificação de estratégias regionais ou lo. cais (para cada área - unidades de conservação como parques, reservas, estações ecológicas etc.), que possam coordenar de forma integrada a preservação ambiental, a melhoria da qualidade de vida das populações e as iniciativas privadas do setor, em harmonia com os demais interesses económicos.

Os recursos financeiros necessários à implantação do ecoturismo devem ser cotejados entre a iniciativa privada, órgãos de governo e instituições de ensino através de mecanismos de incentivo a serem criados. Por outro lado, os recursos financeiros gerados pela atividade devem ser reinvestidos nas unidades de conservação e/ou na região, a fim de viabilizar não só a manutenção dos equipamentos de infraestrutura e hospedagem da população visitante, mas também a efetiva fiscalização destas áreas e promover as pesquisas científicas necessárias.

Observe-se que a falta de uma estrutura organizada não só expōe o turista, como também as populações locais que, além de nada ganhar, sofrem um impacto cultural-econômico, acabando muitas vezes espoliadas das terras que tradicionalmente ocupam, vitimadas pela especulação imobiliária que "grila" e loteia clandestinamente tais áreas. A atividade turística é comumente bem aceita pelas comunidades locais, representando, em tese, um modo opcional de reorganizá-las economicamente, com retorno relativamente imediato. $\mathrm{Na}$ Índia,

(*) Excetuam-se, aqui, algumas raras diretrizes jurídico-institucionais, como. por exemplo, a lei $\mathrm{n}^{\circ} 6.513$ de $20 / 12777$, que dispōe sobre a criaçảo de áreas especiais e de locais de interesse turistico.
Nepal e Thailân

rantes, tidos (assim como o Brasil) como países "em desenvolvimenrantes, tidos (assim como as comunidades locais beneficiam-se das atito", tanto o Estado como as comunida... d d vidades turísticas,

vider licenciamento (autorizações locais) e pagamento de taxas. porém o licencificam-se em alguns casos adequação e controle à capacidade de suporte das estruturas colocadas à disposição dos turistas e monitoramento com técnicos locais devidamente treinados.

No Brasil, porém, são raros os exemplos de áreas e/ou unidades de conservaçã ser citados o Parque Nacional da Floresta da Tijuca (Rio de Janeiro) e a Fazenda Intervales (São Paulo).

\section{PIANEJAMENTO E GESTÃO AMBIENTAL \\ COMO PRÉ-REQUISITO PARA O}

ORDENAMENTO DA ATIVIDADE TURÍSTICA

Sem ter a pretensão de esgotar o tema ou analisar em profundidade a questão do planejamento e gestão do meio ambiente, no contexto da política nacional de meio ambiente ora vigente, destacam-sc neste item três instrumentos fundamentais para estruturar o uso e a ocupaçāo pretendidos pela atividade turístico-ecológica.

\subsection{Zoneamento Ecológico-Econômico}

O zoneamento consiste em dividir um território em parcelas nas quais, a partir de sua vocações/aptidões e de suas fragilidades segundo diretrizes de um plano de desenvolvimento anteriormente definido, são autorizadas determinadas atividades ou interditado de modo absoluto ou relativo o exercício de outras, instruindo um plano de manejo.

A divisão da área objeto de planejamento tem por finalidade orientar investimentos e facilitar o manejo dos recursos naturais, indicando cuidados específicos para cada sub-zona, de acordo com os objetivos previamente definidos para cada unidade em estudo. ${ }^{5}$ Assim cada unidade poderá ser subdividida de acordo com suas potencialidades e fragilidades, em ambientes naturais, áreas urbanas, áreas agrícolas e outras, ressaltando-se a utilização do potencial turístico como um dos critérios que deverá ser sempre analisado e utilizado em tais divisões e contemplado no plano de manejo das áreas quando compatível com a legislação que cria ou destina áreas para a proteção ambiental. 
Uma série de estudos desse tipo foram e estão sendo desenvolvidos pelo Governo de São Paulo, através da atuação de equipes compostas por técnicos das secretarias de estado, universidades e empresas privadas: "Macrozoneamento da Região Lagunar de Iguape e Cananéia"6 (São Paulo), "Macrozoneamento do Litoral Norte", estudos de zoneamento da Fazenda Intervales ${ }^{7}$, do PETAR (Parque Estadual Turístico do Alto Ribeira) e de uma série de APAs (Área de Proteção Ambiental), dentre as quais as de Ilha Comprida e Corumbataí. Para a implementação desses projetos depende-se da viabilização das cireas de proteçāo ambiental, uma vez que as mesmas podem ser definidas como espaços onde as atividades antrópicas são adequadas e compatibilizadas ao uso sustentável dos recursos naturais, mantendo-se a propricdade da terra e a jurisdição municipal sobre elas.

A resolução CONAMA n ${ }^{\circ} 10$ de 14/12/89 estipula critérios relativos ao estabelecimento de zonas de Conservação e Preservação) da Vida Silvestre nas APAs. Os estudos referentes ao Zoneamento e Diretrizes de Desenvolvimento da APA Corumbataís, por exemplo, chegaram até a execução de um Projeto de Lei, que estipula diretrizes para o uso do solo em cada uma das zonas estabelecidas, o qual encontra-se em fase de aprovação. Consideraram-se entre outros aspectos, aqueles referentes ao potencial turístico, identificando-se uma grande quantidade de áreas com relevante valor paisagístico, recreativo e educativo (cuestas e morros testemunho, cachoeiras, cavernas, represas e patrimônio histórico).

É de fundamental importância, portanto, que os estudos de zoneamento contemplem aspectos relativos ao potencial turístico, e indiquem os elementos naturais de particular interesse, bem como os cuidados específicos para as zonas onde os mesmos se situem, conforme o procedimento adotado.

O zoneamento pode ainda surgir acoplado aos planos diretores municipais, posto que a Constituição Federal, em seu artigo 182, relativo à política urbana, obriga as cidades com mais de vinte mil habitantes a elaborarem planos diretores como instrumentos básicos da política de desenvolvimento e expansão urbana. Considera-se, ainda, de fundamental importância que esses planos, além de considerar as zonas urbanas e de expansão, e indústrias, contemplem o estudo do potencial turístico e o levantamento das áreas naturais significativas dentro do município, que não estejam inseridas em unidades de conservação, cujas diretrizes são próprias e específicas.

Os planos de manejo de unidades de conservação por sua vez, são executados com objetivo de proporcionar o desenvolvimento de qualquer tipo de área silvestre, orientando as atividades desenvolvidas de acordo com os objetivos de manejo específicos para cada categoria.
Para tanto o mesmo deve contemplar o zoneamento da área. Particularmente, no caso do "turismo ecológico" tem-se maior interesse não apenas naquelas categorias destinadas ao uso público direto (como Floresta Nacional e APA), mas também nas de uso indireto dos recur sos que permitam a execução de atividade ligada ao turismo controlado e à educação ambiental (nas zonas previstas para esse fim), como os parques nacionais, estaduais e estações ecológicas. ${ }^{9}$

Como excmplos podem ser citados, entre outros, os seguintes planos de manejo, executados em diferentes níveis:

a) federal - Instituto Brasileiro de Desenvolvimento Florestal IBDF*: parques nacionais do Araguaia, de Caparaó, da Serra dos Órgãos e da Tijuca;

b) estadual - Instituto Florestal de São Paulo - IF: parques estaduais de Campos do Jordão, da Cantareira, da Ilha do Cardoso e de Vassununga;

c) privado - área a ser transformada em reserva, dentro da Estância Caiman, no pantanal de Miranda (Mato Grosso do Sul) ${ }^{10}$; nessa propriedade atualmente é recebida uma grande quantidade de turistas nacionais e estrangeiros, atraídos por uma programação que explora os aspectos naturais do pantanal.

\subsection{Estudos de Impacto Ambiental}

A resolução CONAMA n ${ }^{\circ} 001$ de 23/01/86 estabelece uma série de atividades modificadoras do ambiente para as quais devem ser elaborados o Estudo de Impacto Ambiental (EIA) e respectivo Relatório de Impacto Ambiental (RIMA), cabendo ao orgão estadual competente (Secretaria de Meio Ambiente), ou ao município, a fixação das diretrizes adicionais julgadas necessárias) de acordo com as peculiaridades do projeto e características ambientais da área.

Nesse sentido, são normalmente requisitados EIA/RIMAS para marinas, loteamentos rurais e urbanos, estradas (implantação e duplicação), e outros, onde, nos estudos relativos ao meio antrópico, as atividades de lazer e turismo, bem como os monumentos de valor cultural, cênico, histórico e natural a serem afetados ${ }^{11}$ deverão ser considerados.

(*) Atual IBAMA - Instituto Brasileiro de Meio Ambiente e Recursos Naturais Renováveis. 
Ocorre ainda que a atividade turística, enquanto empreendimento potencialmente poluidor e transformador dos espaços naturais, é, em si mesma, analisada no âmbito do estudo de impacto ambiental, onde se procede:

a) ao exame dos eventuais impactos

b) ao estudo da oferta disponível e caracterização das áreas selecionadas para implantação de programas;

c) ao levantamento do patrimônio histórico-cultural, dos recursos naturais e cênicos;

d) à adequaçāo de equipamentos disponíveis ou à implantação a partir da quantificação e periodicidade dos grupos de visitantes;

e) à implantação, incluindo treinamento e capacitação técnico-científica de pessoal;

f) à avaliação, acompanhamento e monitoramento dos programas a serem desenvolvidos e às medidas mitigadoras dos impactos provenientes dessa atividade.

\subsection{Mecanismo de Incentivo}

Uma vez identificado o potencial turístico de um determinado sítio e caracterizados os elementos que compõe o patrimônio natural selecionado, os órgãos governamentais deverão adotar mecanismos de incentivo não só para implementar a atividade turística pretendida, como também para fornecer ou providenciar a infraestrutura, a fiscalizaçảo e o monitoramento necessários.

\section{CONSIDERAÇÕES FINAIS}

É inegável o potencial turístico brasileiro. Além das áreas englobadas por unidades de conservação ambiental (parques, APA's etc.) que abrigam importantes remanescentes da vegetação nativa e fauna endêmica ou cm extinção, diversas regiões como um todo (pantanal matogrossense, floresta amazônica e o litoral como exemplos) deveriam privilegiar o ecoturismo como atividade geradora de riquezas.

Porém, o turismo que se deseja não é o turismo de enclave, desordenado, e sim um turismo planejado e integrado com o meio, que res peite a integridade das áreas de relevante interesse ecológico e o próprio turista, permitindo-lhe aquisição de novos conhecimentos.

Para minimizar os impactos desta atividade propõe-se o estudo de impacto ambiental; a adequaço da infraestrutura à demanda; o incremento, a fiscalização; a participação das comunidades locais; e o respaldo técnico-científico no monitoramento e acompanhamento dos programas.
Além disso, considera-se fundamentalmente importante despertar; através da educação ambiental, as reflexöes sobre os problemas ambientais que colocam em crise o atual tipo de desenvolvimento industrial, não só para os eventuais visitantes, mas principalmente para os municípios que contêm em seus territórios áreas de especial interesse turístico.

\section{REFERÊNCIAS BILBIOGRÁFICAS}

1. COMISSĀO MUNDIAL SOBRE MEIO AMBIENTE E DESENVOLVIMENTO. Nosso futuro comum. Rio de Janeiro, Fundação Getúlio Vargas,1988. 488 p.

2. IUCN. Estratégia mundial para a consen'açào: a consen'açào dos recursos vivos para um desenvolvimento sustentado. São Paulo, CESP, 1984. II, $1 \mathrm{v}$.

3. SÃO PAULO (ESTADO). Secretaria do Meio Ambiente. Coordenadoria de Proteção de Recursos Naturais. Desenvolvimento sustentado: síntese de conferências e painéis do "I Seminário de Desenvolvimento Sustentado" realizado em outubro de 1989. São Paulo, 1991, 80 p. (Série Seminários e Debates).

4. HERCULANO, C.S. Como passar do insuportável ao sofrível. Rev. Tempo e Presença. CEDI (Centro Ecumênico de Documentação e Informação). n. 261. 1992, p. $12-5$.

5. MILLER, R. Planificación de parques nacionales para el ecodesarrollo em Latinoamerica. FPMA, $1980,500 \mathrm{p}$.

6. SĀO PAULO (ESTADO). Secretaria dos Negócios do Interior. Superintendência do Desenvolvimento do Litoral Paulista - SUDELPA. Plano básico de desen'olvimento auto-sustentado para a regiào lagunar de lguape e Cananéia. São Paulo. $1987,89 \mathrm{p}$.

7. BARBOSA, L.M., BONONI, V.L. \& MANTOVANI, W. Zoneamcnto agroccolśgico da Fazenda Inten'ales. São Paulo, Secretaria de Meio Ambiente/Fundação Florestal, 1989, 20 p. (texto datilografado).

8. ENGEA - Avaliaçōes, Estudos do Patrimônio e Engenharia Ltda. Elaboração de zoneamento ambiental e parâmetros de controle, restriçöes de uso e ocupação do solo. insumos técnicos a serem utilizados para a regulamema çào da área de proteçào aımbiental Conumbatat - Botucatu - Tejubá. Pcrimetro Conumbataf. São Paulo, Secretaria do Meio Ambiente, 1990, $17 \mathrm{v}$.

9. FUNATURA. Sistema nacional de unidades de consen'açũo. Brasília. FUNATURA. $1989,44 \mathrm{P}$.

10. RIBEIRO. W. Plano de manejo: resen'a ecológica do Pantanal. Piracicaba. ESALQ/USP, 1987, $129 \mathrm{p}$

11. SĀO PAULO (ESTADO). Secretaria do Meio Ambiente. Coordenadoria de Planejamento Ambiental. Estudo de impacto ambiental - EIA, Relatório de impacto ambiental - RIMA: Manual de orientação. São Paulo, 1989, 48 p. (Sćrie Manuais). 